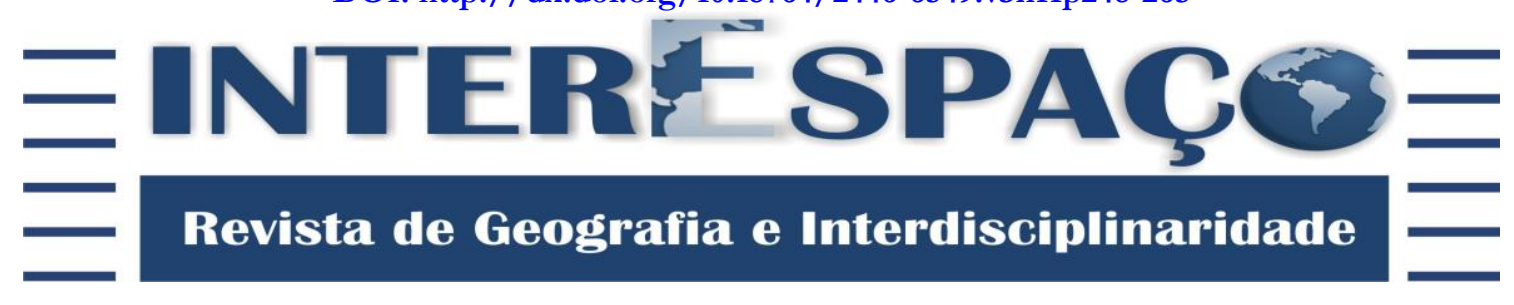

\title{
ENTRE COMPORTAMENTOS, DISCERNIMENTOS E DESENVOLVIMENTOS: os sujeitos da aprendizagem em quatro movimentos
}

\author{
BETWEEN BEHAVIOR, INSIGHTS AND DEVELOPMENTS: \\ The subjects of learning in four movements
}

ENTRE COMPORTAMIENTOS, DISCERNIMIENTOS Y DESARROLLOS: Sujetos del aprendizaje en cuatro movimientos

\begin{abstract}
Samuel Edmundo Lopez Bello
Doutor em Educação pela Universidade Estadual de Campinas - UNICAMP. Professor da Faculdade de Educação e do Programa de Pós-graduação em Educação da Universidade Federal do Rio Grande do Sul - FACED/PPGEDU/UFRGS. samuel.bello@ufrgs.br

\section{Diego Souza Marques}

Doutor em Educação pela Universidade Federal do Rio Grande do Sul - PPGEDU/UFRGS. diego.souzamarques@gmail.com

Recebido para avaliação em 19/01/2017; Aceito para publicação em 18/11/2017.

O presente artigo tem por objetivo problematizar a relação entre algumas concepções de aprendizagem e a produção de formas sujeito no campo educacional. Desdobrando tal aproximação, discutimos o que poderia ser a emergência dessas formas sujeitos que aprendem no comportamentalismo de Skinner, na Gestalt de Köhler e no desenvolvimento de Piaget e Vygotsky. Tais concepções foram selecionadas para serem revisitadas devido a sua relevância na área da psicologia da educação e sua ressonância que resiste ao entendimento do que poderia ser o processo de aprender. Destacando a questão a partir de enfoques teóricos inspirados na formação discursiva proposta por Michel Foucault e nos estratos subdivididos em visível e enunciável de Gilles Deleuze, entendemos as citadas abordagens psicológicas como produtoras de determinadas tipologias de sujeitos como resultados dos processos de aprendizagem. Buscamos, desta maneira, descrever como se dão estes movimentos de aprendizagem e a produção de sujeitos, destacando a positividade e a especificidade de cada perspectiva discursiva e estratégica.
\end{abstract}

Palavras-chave: Teorias da Aprendizagem; Sujeito Discursivo; Psicologia do Desenvolvimento.

\section{ABSTRACT}

The present article aims to problematize the relationship between some conceptions of learning and the production of subject forms in the educational field. Unfolding such an approach, we discussed what might be the emergence of these subject forms that learn in Skinner's behaviorism, Köhler's Gestalt, and the development of Piaget and Vygotsky. Such conceptions were selected to be revisited because of their relevance in the field of educational psychology and its resonance that resists the understanding of what could be the process of learning. Highlighting the issue from theoretical approaches inspired by the discursive formation proposed by Michel Foucault and in the strata subdivided into visible and articulable by Gilles Deleuze, we understand the mentioned psychological approaches as producers of certain types of subjects as results of learning processes. 
Dossiê: Diálogos interdisciplinares em Psicologia da Educação

| Entre comportamentos, discernimentos e desenvolvimentos: os sujeitos da aprendizagem em quatro movimentos |

| Samuel Edmundo Lopez Bello | Diego Souza Marques |

In this way, we seek to describe how these learning movements and the production of subjects, highlighting the positivity and specificity of each discursive and strategic perspective.

Keywords: Theories of Learning; Discursive Subject; Developmental Psychology.

\section{RESUMEN}

Este artículo tiene como objetivo discutir la relación entre algunas concepciones de aprendizaje y la producción de formas sujeto en el campo educacional. Desplegando tales relaciones, discutimos lo que podría ser la aparición de esos sujetos que aprenden explicitados por el conductismo de Skinner, la Gestalt de Köhler y las psicologias del desarrollo de Piaget y Vigotsky. Fueron seleccionadas esas concepciones para ser revistas dada su relevancia en el área de la psicología de la educación y los ecos que permanecen en la comprensión de lo sea el acto de aprender. Tomando esta discusión a partir del enfoque teórico propuesto por Michel Foucault, en lo que se refiere a las formaciones discursivas, así como en los estratos de lo visible y decible de Gilles Deleuze, los citados enfoques psicológicos son entendidos como productores de ciertos tipos de sujetos con base en los procesos de aprendizaje que ellos mismos describen. De esta manera procuramos describir los movimientos que se dan entre el aprendizaje y la producción de sujetos destacando lo positivo y la especificidad de cada perspectiva discursiva y estratégica.

Palabras clave: Teorias del Aprendizaje; Sujeto Discursivo; Psicologia del Desarrollo.

\section{INTRODUÇÃO}

A aprendizagem, como objeto que opera algo, pode ser inserida em abordagens educacionais preocupadas com certo tecnicismo em seu processo. Destacada em contextos do início do século $\mathrm{XX}$, onde tanto os mecanismos de ensino como as organizações curriculares almejavam objetivos considerados “acríticos” ou "tradicionais" (SILVA, 1999), perdeu, ao longo do tempo, o status privilegiado em teorizações no campo da educação. Dizemos isso para salientar que aprender, como movimento mirado pela constituição de saberes educacionais, ganhou contemporaneamente certos contornos subordinados a objetivos mais amplos. Seja como movimento cognitivo que busca um desenvolvimento mental, contorno de problemas específicos ou adaptação social, a aprendizagem é espaço de passagem para isto que é colocado como amplitude em formações modernas e humanísticas. Aprender é território para outra questão considerada mais fundamental que ela, e, como todo campo de passagem na modernidade, é lugar de disputas e de desvios.

Dentro deste espaço em que a aprendizagem é alocada como maneira de alcançar objetivos dentro de determinada perspectiva, iremos, no presente artigo, destacar as formas sujeito que ela almeja delimitar. Qual a concepção de sujeito implicada em alguns arranjos conceituais que tomam a aprendizagem como objeto de saber? Como formação discursiva ${ }^{1}$

\footnotetext{
${ }^{1}$ Entendemos formação discursiva a partir da proposta de Michel Foucault (2010) em $A$ arqueologia do saber. Como maneira de se diferenciar de termos como teoria ou ideologia, a formação discursiva pressupõe práticas de saber que formam objetos, conceitos, lugares de sujeitos ou mesmo teorias em sua configuração.
} 
Dossiê: Diálogos interdisciplinares em Psicologia da Educação

| Entre comportamentos, discernimentos e desenvolvimentos: os sujeitos da aprendizagem em quatro movimentos |

| Samuel Edmundo Lopez Bello | Diego Souza Marques |

que enquanto cria seu objeto, também delimita as posições de sujeito simultaneamente, algumas psicologias da educação irão torna-lo a origem do conhecimento enquanto é transformado por ele. O sujeito é, ao mesmo tempo, um espaço criado pelo próprio arranjo da abordagem enquanto ela o pressupõe como anterior ao que quer descrever. Nesta reciprocidade há peculiares formações, seja em aquisições de comportamento de um behaviorismo ou em um desenvolvimento piagetiano. Assim, nestas abordagens, há um sujeito que já existe anteriormente ao processo, mas nunca está plenamente formado enquanto não atravessar determinados estágios de transformação.

Tendo em vista o conceito de formação discursiva vamos revisitar quatro autores centrais para as psicologias da educação que impactaram o tema da aprendizagem e as formas sujeito decorrente dela. Em primeiro lugar iremos destacar um sujeito comportamental, formado a partir da perspectiva reforçadora do behaviorismo. Após, discutiremos um sujeito que se compõe como perspectiva em relação a um todo, resultante das conceitualizações das psicologias da Gestalt. Na sequência, um sujeito que se configura como desenvolvimento será divido em duas vertentes, uma atribuída à epistemologia genética de Jean Piaget e a outra ao desenvolvimento social de L. Vygotsky. Assim, os sujeitos que são resultados de processos de aprendizagem se mostram como possíveis dentro das formações que os criaram.

Tais movimentos foram selecionados pela sua regularidade como aparição em currículos de formação de docentes. Outras tantas abordagens poderiam ser adicionadas de acordo com o recorte que propomos. A limitação se deu pela centralidade que ocupam estas perspectivas em relação à movimentos posteriores no campo da psicologia da educação e da aprendizagem. Tratar, por exemplo, da questão da cognição como autopoiese, já profundamente abordada por Virgínia Kastrup (1999), seria um exercício de prolongamento de questões já postas por uma perspectiva piagetiana no que diz respeito à produção de um sujeito. Do mesmo modo, as múltiplas inteligências de Howard Gardner (1994) tão desdobradas e por onde tantas investigações já se debruçaram, novamente, em relação ao sujeito, poderiam soar como redundância enquanto vemos - especificamente neste aspecto - uma ressonância desenvolvimentista com teores tanto de Piaget como de Vygotsky. Assim, a delimitação criou, na presente investigação, limites que levaram em conta uma função específica de concepção de sujeito, o que não depende necessariamente da forma como se entendem o conhecimento e aprendizagem.

Optamos, no presente artigo, por nos ater aos termos objetos e lugares de sujeito, tanto para especificarmos o recorte quanto para traçar paralelos com a leitura deleuziana que se atém ao visível e ao enunciável. 
Dossiê: Diálogos interdisciplinares em Psicologia da Educação

| Entre comportamentos, discernimentos e desenvolvimentos: os sujeitos da aprendizagem em quatro movimentos |

| Samuel Edmundo Lopez Bello | Diego Souza Marques |

Conforme dito anteriormente, a criação de objetos e lugares de sujeitos são imanentes às próprias formações discursivas que, mesmo que indiretamente, tratam do problema da aprendizagem. Esta escolha metodológica está baseada em Michel Foucault (2010), principalmente no que tange às suas abordagens da questão do saber e sua propositiva arqueologia. Ao mesmo tempo, em um sentido mais dinâmico para a produção destes sujeitos dentro de determinados registros, destacaremos a leitura feita por Gilles Deleuze (2005) das questões formuladas por Foucault. Neste movimento, o sujeito não está somente dependente de uma posição em uma formação discursiva, mas se desenrola a partir de uma repartição de um estrato de saber o que o filósofo chama de enunciável e visivel. E nesta fenda há um espaço de produção de certas formas sujeito que se transmuta, inclusive dentro de um estrato de saber que solidifica uma concepção de aprendizagem.

O enunciável e o visível são repartições das estratificações de saber. As suas configurações deixam exposto o que pode ser dito e visto em determinada formação relativamente já solidificada. Deixam marcas mais duras, estratificadas ou, em outra perspectiva, linhas molares mais difíceis de serem transformadas (DELEUZE \& GUATTARI, 2012). Os estratos deixam fissuras, porém mais efêmeras e às vezes demasiadamente já configuradas para que algo que aparentemente novo pudesse se encaixar nelas. Assim, por exemplo, uma abordagem que enuncia que a aprendizagem depende de estruturas já pré-existentes em um sujeito ainda não formado poderiam soar como transformadora, mas o arranjo do estrato já permitia que este enunciável e visível se colocasse como algo novo, embora efetivamente não fosse. Os estratos enunciáveis e visíveis permitem movimentos novos, mas já programados pois são delimitados pelo possível.

É no interior desta repartição podem emergir sujeitos. Não entendidos como posições pré-definidas como em uma formação discursiva, mas determinadamente cambiantes como nascidos no espaço que se dá entre o enunciável e o visível. Da não relação conectada dos dois polos dos estratos há espaços para o surgimento de concepções de sujeitos que precisam se formar a partir de contatos com enunciáveis e visíveis que irão dar a eles características compartilhadas e multifacetadas. Tomando como exemplo as formações que iremos abordar, um sujeito que se constitui nas fissuras da psicologia Gestalt irá se desenrolar enquanto se movimenta nos espaços criados pelas consistências internas do que este saber produz como enunciabilidades e visibilidades. Isto é, estes sujeitos são efeitos destas práticas, como uma curva que deriva e, ao mesmo tempo, retorna para dar 
Dossiê: Diálogos interdisciplinares em Psicologia da Educação

| Entre comportamentos, discernimentos e desenvolvimentos: os sujeitos da aprendizagem em quatro movimentos |

| Samuel Edmundo Lopez Bello | Diego Souza Marques |

corpo a algo que aparentemente poderia se configurar como abstração. Assim, as subjetividades se formarão nas teceduras das composições de tais estratos.

\section{O SUJEITO DO COMPORTAMENTO}

Na curva derivada dos saberes e poderes, o sujeito pode se constituir como algo multifacetado, ou multicorpóreo, que se transforma a cada novo movimento. No avançar e/ou retroceder deixa em suas bordas marcas, quase como espectros de forma opaca, onde se é capaz de perceber o que será e o que deixou de ser. Nesse registro de leves configurações somente percebido pelo seu efêmero repouso, não há profundidade em sua existência, mas sim auras que se espalham por uma superfície visível e enunciável. O sujeito não é interior e essencial, mas somente encadeamentos de causas e consequências observáveis pelo seu desenrolar. O sujeito se transforma em comportamento.

Um "repertório de comportamentos" (SKINNER, 1974, p. 130) que faz de si série de ações, tendo consciência de si a partir de sua capacidade de reprisar o seu trajeto pelicular. E este fluxo tem um ambiente no seu processo. "Uma pessoa não é um agente que origine, é um ponto em que múltiplas condições se reúnem em efeito conjunto" (SKINNER, 1974, p. 145). As diferentes movimentações deste sujeito que se contorce respondem àquilo que o enredo a ele coloca como contingência, mesmo que à primeira vista soe como um roteiro pré-estabelecido. O sujeito que se manifesta como mudança de comportamento recebe suas linhas de demarcação do exterior. Não há uma interioridade que enquadre o ambiente de acordo com um ponto de vista ou subjetividade, mas fragmentos que se encaixam a partir daquilo que o cenário exige. As demandas não são previsíveis, e a capacidade de consciência deste sujeito só pode dizer a si mesma "eu sou" enquanto adquire contornos que respondem ao que está sendo exigida dela. Indo ainda mais longe podemos dizer: ela reage para poder existir.

As ações mais adequadas a um sujeito que se reconhece como tal estão pautadas na melhor maneira como responde aos acasos que o meio proporciona. Ter alguma sensação boa ou mesmo um progresso não são as melhores respostas. Elas são consequências de um longo processo seletivo que as faz emergir como melhores opções ou não para sua constituição. O comportamento efetivamente delimitado, de onde se extraí um sujeito aquele que vai se repetir seja como reconhecimento de um eu, memória ou mesmo conhecer a si - é fruto de um reforço. E por mais que subestimemos o sentido dessa noção, 
Dossiê: Diálogos interdisciplinares em Psicologia da Educação

| Entre comportamentos, discernimentos e desenvolvimentos: os sujeitos da aprendizagem em quatro movimentos |

| Samuel Edmundo Lopez Bello | Diego Souza Marques |

quando podemos encará-la como satisfação de desejo, por exemplo; ela se mostra muito mais intensa e ao mesmo tempo mais básica: é questão de sobrevivência.

Selecionar os próprios comportamentos e buscar repeti-los é resultado do reforço. Quando positivo, se transformará em objetivo, repetição pela sua coleção de diferenças de grau e consequentemente formação identitária de um sujeito. De início, tal comportamento pode ser inconsciente ou mesmo irracional, pode-se fazer tal ação mesmo sem saber por que fazê-la. O sujeito em formação pode estar perdido em meio ao labirinto, encontrar a saída por "intuição", mas a repetição garantirá um quinhão de regularidade no que inicialmente soa como mero acaso.

E é justamente nesta evolução, entendida como um comportamento reforçado pela adaptação e que resulta em um sujeito consciente de si e do mundo exterior a ele, que atua a aprendizagem como elemento essencial. "Procurar alguma coisa é comportar-se de maneiras que foram reforçadas quando se achou alguma coisa" (SKINNER, 1974, p. 88). As teorias educacionais estariam mergulhadas em um mentalismo, onde o desenvolvimento iria na direção da capacidade de abstração do pensamento. O sujeito comportamental que aprende não está se configurando por tais exercícios de teorização do conhecimento, mas sim em práticas que garantam seu melhor desempenho na adaptação.

A aprendizagem se exerce como processo que possibilita a criação de modos de desenvolturas resultantes daquilo que deve ser feito para a melhor adaptação ao que está posto como obstáculo. Mudar o mundo circundante entendido como ambiente é também mudar as necessidades e, por isso, os reforços devem se refazer como exigência de novo aprendizado. Assim, aprender, para a formação de um sujeito comportamental, é readaptar às novas situações impostas ocasionalmente pelo mundo exterior a subjetividade composta por essa necessidade em armazenar diferentes formas de agir e de ser.

Poderíamos dizer que a questão da aprendizagem na produção deste sujeito comportamental está centrada naquilo que se faz e não em faculdades mentais. Obviamente, aquilo que se faz em um sentido de adequar as ações para que um desempenho ou uma performance de sobrevivência e adaptação se sobressaiam na legitimação deste sujeito, agora considerado pleno em seu existir. E esta constância que pode afirmar sua consolidação como indivíduo, depois de todos os processos e transformações que discutimos, só é considerada real quando faz de si mesma um hábito. O que a primeira vista poderia soar como instinto, como a questão do comportamento que se molda como identidade a partir da contingência que exige uma maneira de se adaptar para sobreviver; torna-se hábito na medida em que refina e privilegia o reforço como um 
Dossiê: Diálogos interdisciplinares em Psicologia da Educação

| Entre comportamentos, discernimentos e desenvolvimentos: os sujeitos da aprendizagem em quatro movimentos |

| Samuel Edmundo Lopez Bello | Diego Souza Marques |

salto além da mera reação. Ser hábito é parte de um processo ativo na reação. Ser hábito torna-se sinônimo do já citado sujeito entendido como repertório de comportamentos.

E o hábito é o resultado efetivo da aprendizagem que dobra o reagir ao ambiente aparentemente caótico em um comportamento previsível a qualquer outro tipo de contingência.

A humanidade não evoluiu de acordo com um plano implícito, evoluiu através da seleção sob a contingência da sobrevivência, como o comportamento verbal da criança evolui sob a ação seletiva das contingências de reforço (SKINNER, 1974, p. 88).

E neste ponto da curvatura em que um sujeito pleno circunscreveu seu repertório de comportamentos pode ser dito e visto: houve aprendizagem.

Vimos que o sujeito resultante de todo esses processo se forma a partir do seu desenrolar detectável, não apenas como um corpo em um laboratório, mas também como desempenho em um ambiente entendido como a própria vida. Deste sujeito identificável pelos seus fragmentos de diferentes ações, há uma unidade a partir do momento em que há uma normalidade adaptativa, que entende todos os desvios como reação que pode ser repetida, desde que a aprendizagem dê conta de flexibilizar adequadamente suas diversas características. Produzir determinado sujeito, como resultado de uma aprendizagem comportamental, é deixar possíveis moldes não concretos como lugares onde ele pode se encaixar e se transformar apenas como algo medível nestes espaços.

\section{O SUJEITO DA PERCEPÇÃO}

Agora o sujeito não é o resultado de um cruzamento de linhas que possibilitam espaços diversos para o seu repertório de movimentos nos ambientes. Ele tornou-se, como emergência de uma nova estratégia atuando sobre um estrato, espaço de associações. Não vazio e muito menos mero ponto de passagem, mas uma espécie de encruzilhada gravitacional que faz o seu destaque somente ser constatado pela sua relação com o que está ao seu redor. Um brilho que realça seu entorno, como uma existência que se destaca na medida em que se desloca o olhar e o dizer sobre ele. O sujeito torna-se percepção.

Tal formação de sujeito se dá além das condições fisiológicas do organismo e sua correspondente organização mental entendida como capacidade de abstração. Entre essas duas ligações existe algo que se chama de "eu" e que é uma experiência perceptiva, tanto do corpo e da mente quanto do mundo exterior. Tanto as experiências sensoriais quanto os 
Dossiê: Diálogos interdisciplinares em Psicologia da Educação

| Entre comportamentos, discernimentos e desenvolvimentos: os sujeitos da aprendizagem em quatro movimentos |

| Samuel Edmundo Lopez Bello | Diego Souza Marques |

significados que se extraem delas somente são substâncias para a densidade de uma identidade quando estabelecem elos que as colocam em transversalidade e ao mesmo tempo as ultrapassam. Assim, o sujeito que se estabelece na percepção não é uma trajetória de comportamentos, mas união de independências que de alguma forma se ligam, tanto interiormente quanto externamente.

Por tal configuração, em um primeiro momento é de difícil individuação uma identidade subjetiva em relação ao seu entorno. O sujeito está camuflado e os seus contornos limítrofes não podem ser percebidos sem que haja exercícios que o façam emergir como algo visível e enunciável. Certo corte é necessário, algo de descontínuo é necessário para que uma consciência que se reconheça como existência se destaque em meio a um fundo que soa uniforme e indiferente. Como um aparente paradoxo, o que faz desse pano de fundo impessoal uma composição de individuações são as associações.

O que poderia ser um espaço liso e sem diferenciações é transformado em sinuosas partes a partir do jogo das associações. Algo se conserva, como um pequeno traço que por qualquer efêmera semelhança liga e destaca um ponto qualquer do outro. E nesta oscilação entre continuidade e estriamento, associações vão operar como uma função, se revezando entre definir a unidade do sujeito e colocá-lo como parte de um espaço ampliado, que não distingue mais somas de partes, e sim transbordamento de ligações não mais observáveis. Ser função é ocupar uma posição relativa de como vai se configurar esse todo e, por isso, o sujeito é um ponto de vista nessa relação que vai se definir como tal dependendo de uma percepção.

Esta produção de um sujeito relativo depende de traços vetoriais que o localizam e o distanciam ao que está associado. Cada uma destas linhas vai determinar parcialmente sua função nesta rede de ligações e, assim, formar unidades parciais que vão se conectar a diferentes percepções para que ele se individualize. Para que a associação na qual emergirá esse transitório sujeito perceptivo não seja um sem fim de possibilidades que apenas manteriam conjuntos sem nunca os distinguir, é necessária uma evocação como característica inibidora. O resultante deste movimento são sobrevivências de traços unitários no processo de associação e, por isso, este sujeito que só se destaca em relação ao que está ao seu redor pode compor linhas móveis de identidade que o ligam a um passado que se mantém relativamente contínuo. A história desse sujeito pode ser contada a partir das diversas maneiras como ele se relacionou ao todo. “Eu” é mutável em relação ao campo [...] está se dirigindo ou se afastando de algo” (KÖHLER, 1980, p. 173). 
Dossiê: Diálogos interdisciplinares em Psicologia da Educação

| Entre comportamentos, discernimentos e desenvolvimentos: os sujeitos da aprendizagem em quatro movimentos |

| Samuel Edmundo Lopez Bello | Diego Souza Marques |

Evocar depende da aprendizagem; é quase uma consequência dela. Ela permite definir, enquanto movimento em que a vida se encarrega de exigir ou não, os traços associativos que mais tarde valerão a pena ser evocados. E os seus resultados não dependem de uma habilidade adaptativa como antes, mas como simplesmente uma capacidade de distinguir onde começa o que está fora e onde termina o que está dentro. $\mathrm{O}$ sujeito perceptivo que se forma nesta concepção não aprende para seguir parâmetros de ultrapassar algo similar à seleção natural, mas de alcançar uma consciência do seu lugar nesse todo; seja no sentido de se destacar, seja no sentido de se conectar. A aprendizagem ganha contornos, neste caso, como um processo onde ocupa-se um espaço na composição de uma organização.

A aprendizagem corresponde, relativamente, à associação. Mas nestes desenvolvimentos de ligações que podem se repetir para que surja um sujeito, ela se define como um instante dialético que envolve semelhança e diferenciação. No interstício entre isolamento e unificação que corresponde, neste caso, ao movimento de associação e individuação, a aprendizagem atua ao mesmo tempo em que se define como um território de conexão não causal entre o que faz surgir uma brecha que se pode entender como sujeito e uma ponte que faz ele ser parte de algo maior. Não causal pelo fato de possibilitar ao invés de determinar. Dialética por sintetizar essas posições ao mesmo tempo em que faz parte das duas simultaneamente. A aprendizagem que faz parte da formação do sujeito perceptivo é espaço de síntese não totalizadora; onde o ponto de encruzilhada cria deslocamentos à sua adequação ao meio que buscava adequá-la.

O sujeito perceptivo que resulta de uma aprendizagem que o organiza entende o meio que o circunda como apenas uma função que o vai associar e/ou individuar? Soa justo pensar que o meio entendido neste caso não se assemelha ao ambiente que rodeia o sujeito comportamental, afinal, se organizar nesta relação não corresponde a se adaptar a uma exterioridade que lança contingências. Estamos mais próximos de um registro de meio que se entende como uma disposição onde certos aspectos dele vão se complementar para formar um espaço que, se não restritamente totalizante, ao menos irá relativamente se definir como um todo. E nesta amplitude o sujeito perceptivo vai atuar se destacando ou se confundindo dependendo de onde se focam as suas linhas de composição. Mesmo que contrastes ajudem em sua definição, as contiguidades também são necessárias para formar esse todo que se destaca do sujeito ao mesmo tempo - e somente neste momento, também pela sua uniformidade. 
Dossiê: Diálogos interdisciplinares em Psicologia da Educação

| Entre comportamentos, discernimentos e desenvolvimentos: os sujeitos da aprendizagem em quatro movimentos |

| Samuel Edmundo Lopez Bello | Diego Souza Marques |

Neste jogo torna-se importante o conceito de discernimento. A camuflagem deste sujeito em relação ao todo depende, para se desfazer, de certas inclinações para que ele se destaque e se entenda como tal. Difícil se confundir com o meio, já que a tendência é se entender como parte isolada deste mesmo entorno; mas mais complicado ainda é formar-se sujeito em um processo que pressupõe o destacamento, dependente de uma percepção, ao mesmo tempo em que exige as associações e posteriores conexões em relação a ele (evocação). A camuflagem é acompanhada de sinuosos traços de diferenciação, e a reativação desta sutileza depende da aprendizagem. O discernimento, assim, atua como a consciência que discrimina o que aparentemente parecia como incontornável.

Discernir é criar um juízo sobre estas insistentes relações de associação, organização e diferenciação. O juízo formado - depois das repetidas evocações e que com o aprendizado tornaram-se úteis a esta convivência com o exterior (organização) - é a determinação, sempre provisória e cambiante, da emergência de um sujeito perceptivo. "Concentrar a atenção em fenômenos ampliados que se distribuem e se regulam como conjuntos funcionais" (KOHLER, 1980, p. 104). A organização é resultado da aprendizagem como configuração anterior de um sujeito que está para ser formado. $O$ discernimento é a maneira como este sujeito, já previamente moldado por si mesmo, encara esta nova forma de lidar com àquilo que está ao seu redor. E nesta etapa de olhar para o todo, depois que houve uma organização interna em relação ao mesmo exterior, a circunscrição de um eu vai desenhar melhores opções de se encaixar com este espaço mais amplo. O discernimento é a capacidade de julgamento que faz de nós sermos considerados sujeitos.

\section{O SUJEITO DO DESENVOLVIMENTO: além do objeto}

O sujeito não é uma forma que cresce de uma fase para o outra como um jogo onde há estágios numeráveis. Se desenrola a partir de uma reação em que contam a sua capacidade de absorver e de adaptar o que vem do exterior para ele. Nesta dupla via, em que ele está quase como um solitário lidando com algo que vem de dentro e de fora, pode se constituir dosando as medidas enquanto é capaz de canalizar o que se adapta e o que se transforma. Nesta corda bamba em que nunca se firma definitivamente o trajeto e que não se alcança uma queda identitária, há uma afirmação oscilante quando o passo a passo cambaleante é considerado uma ampliação das capacidades. O sujeito implicado nesta atração perigosa do dizer e do ver é produzido como desenvolvimento. 
Dossiê: Diálogos interdisciplinares em Psicologia da Educação

| Entre comportamentos, discernimentos e desenvolvimentos: os sujeitos da aprendizagem em quatro movimentos |

| Samuel Edmundo Lopez Bello | Diego Souza Marques |

Sendo originário e produto ao mesmo tempo, o sujeito do desenvolvimento somente se reconhece como tal em relação. E o seu par nesta necessidade de limite do que é ele encontra-se nos objetos, entendidos como não sujeitos ou exterioridades que o encaram. Ele se apoia neste objeto que está separado dele, faz dele o seu duplo para que em ligação se extraia um conhecimento, mesclando uma identidade junto à sua alteridade. E nesta interação cria-se uma zona indiferenciada, que por algum momento dissolve os dois polos na relação para depois separá-los ampliado a capacidade de consciência do mesmo sujeito, agora desenvolvido e novamente apartado do objeto.

A interação, seja entendida como choque ou necessidade, não é um intercâmbio de formas separadas. Isso acontece depois, desenvolvendo uma nova identidade. Enquanto se desdobra, ela não distingue os pontos que estão em conexão, fazendo desta troca apenas um mediador para a emergência de uma consciência. O dizer e o ver, neste caso, de onde deriva uma forma sujeito não o está repartindo em diferentes perspectivas, mas desenhando traços onde há um correspondente objeto junto a ele em cada maneira dele ser um resultado. Cada dizer e cada ver desenrolando este sujeito tem naquilo que não é visto e nem dito um necessário paralelo em sua gênese. $\mathrm{E}$ o resultado desta interação momentaneamente indiferenciada em enunciabilidades e visibilidades compõem parte do processo que se dá quando se alcança um relativo equilíbrio.

Os subsequentes processos de equilibração formam um conjunto mais amplo que é o próprio desenvolver-se. Assim, o sujeito que se constitui como desenvolvimento terá um longo caminho em sua formação, sendo, portanto, o resultado de um longo processo subdividido, onde cada estágio irá compor mais uma peça nesta formação dependendo de constantes desequilibrações/equilibrações. Desequilibrar pressupõe uma necessidade, um chamamento dos objetos a uma compensação ou resposta do processo de formação do sujeito. Desequilibrar é também perturbar esta identidade em formação de maneira que ela terá que incorporar fragmentos novos destes objetos e reajustá-los a sua ampliação de consciência. E a consequente reequilibração será o momento em que houve um balanceamento destes termos que resultou em uma necessidade e consequentemente deixou novas brechas para o próximo movimento.

O desenvolvimento agrega cada etapa que finaliza estas sínteses, e, por isso, a formação do sujeito do desenvolvimento é dividida em estágios. Todo este arranjo se movimenta em direção à uma espécie de grande balanceamento final; quando há de fato uma identidade subjetiva capaz de tanto prever novas demandas acessando seu repertório 
Dossiê: Diálogos interdisciplinares em Psicologia da Educação

| Entre comportamentos, discernimentos e desenvolvimentos: os sujeitos da aprendizagem em quatro movimentos |

| Samuel Edmundo Lopez Bello | Diego Souza Marques |

quanto de interpretar representativamente àquilo que passou de acordo com as características de sua identidade já consciente.

O duplo movimento de interiorização e de exteriorização que começa desde o nascimento vem garantir esse acordo paradoxal de um pensamento que se liberta enfim da ação material e de um universo que engloba esta última, mas a ultrapassa de todas as partes. Este acordo é fruto de longas séries correlativas de construções novas e não pré-determinadas, partindo de um estado de confusão indiferenciada de onde aos poucos se destacam as operações do sujeito e a causalidade do objeto (PIAGET, 1999, p. 30).

E é esta relação do sujeito com o objeto, proporcionando as sínteses de conhecimento que vão direcionar a realização de uma identidade. Em todas as fases que ora se sucedem e ora coexistem nesta relação criará novos equilíbrios que irão desenvolver a consciência de um sujeito até que finalmente ele possa se compreender como tal. Todos os duplos movimentos, conforme dito na citação, irão se suceder até que algo se destaque, ou seja, o sujeito que age e escolhe junto ao reconhecimento de um objeto que também é sua causa.

O sujeito, depois de constituído, é capaz de representar, classificar e, principalmente, conceitualizar os objetos que estão ao seu redor. Se anteriormente tínhamos a busca de um destacamento provisório em relação as associações dependentes da maneira como se organiza uma percepção, agora temos uma hierarquia bem definida, apesar da momentânea dependência de uma relação. E nestas passagens dos desequilíbrios e novos equilíbrios necessários atua a aprendizagem como uma liga que conecta o fim de um processo e o início do próximo. "A aprendizagem é somente um aspecto do desenvolvimento" (PIAGET, 2007, p. 94). Ela é a esteira da modificação constante e duradoura rumo ao encadeamento pleno de uma identidade capaz de se colocar acima das relações das quais antes era dependente. Aprender é delimitar um espaço de antecipação para um novo desequilíbrio.

E para que esta súbita identidade saia de sua imersão em relação com objetos há um necessário exercício de assimilação. Quando os objetos que perturbam a existência provisória de um sujeito que está não conscientemente se entendendo como tal estão se rebatendo em relação a ele como posições diferenciadas um respiro não voluntário faz disso uma aprendizagem como ponte para um possível desenvolvimento. Estes dados que não faziam parte da efêmera identidade a se criar penetram a sua estrutura como novas oscilações que fazem do entendido já organizado apenas um ponto de passagem. Incorporar isto que é exterior e relativamente novo ao que já estava arranjado como maneira de se entender 
Dossiê: Diálogos interdisciplinares em Psicologia da Educação

| Entre comportamentos, discernimentos e desenvolvimentos: os sujeitos da aprendizagem em quatro movimentos |

| Samuel Edmundo Lopez Bello | Diego Souza Marques |

como um "eu sou" depende da acomodação; dupla inevitável da assimilação. E neste processo a aprendizagem faz delas uma concordância inevitável, pois já preparou o terreno para a nova necessidade de assimilação/acomodação. A aprendizagem antecipa e pactua a assimilação e a acomodação.

Tudo é estágio no sujeito que emerge de uma aprendizagem do desenvolvimento. Seu desenrolar depende de cada minúcia de um momento bem característico em sua composição. O dizer e o ver que o originam estão em consonância ao afirmar sua dependência em relação aos objetos e as suas exterioridades, formando assim outro par de duplos. A aprendizagem é um ponto de passagem entre um estágio e outro, balizando a assimilação e a acomodação como revezamentos necessários para a sua constituição como movimento que salta de um para o próximo. Ser um sujeito, neste caso, depende de um desenvolvimento que leva em conta estes diferentes estágios de complementaridade.

Os sujeitos anteriores dependiam de distintos processos para se constituir. O reforço era algo fundamental para compor uma identidade calcada na acumulação de um repertório de possíveis comportamentos. Mesmo que em metamorfose, o sujeito adquiria certas dobraduras que podiam se repetir e se constituíam como uma repetição constatável. Depois, o sujeito constituído poderia evocar certos traços de associação em relação com um meio que às vezes o ligava a uma continuidade e às vezes o destacava por sua individualidade, dependendo de certa percepção. Agora temos um sujeito que se desenvolve por estágios a partir do momento que vai configurando sua relação de dominação em relação aos objetos que o separam e o definem como determinação. Assim, a subjetividade que se desenha com fortes traços a partir de um desenvolvimento vai se definindo como algo que deixa clara a sua posição em relação à conexão que tem dependência para se entender como tal. De certa forma, podemos dizer e ver que ser sujeito do desenvolvimento é adestrar os objetos que ao mesmo tempo o afirmam como um.

\section{O SUJEITO DO DESENVOLVIMENTO: aquém do social}

O raciocínio antecede o sujeito. Raciocinar não será uma maneira de resolver problemas que o separará, por exemplo, de outras espécies. Em um desenrolar temporal haverá uma sobreposição de duas formas distintas de enquadrar e compreender a si mesmo e o mundo ao redor. Uma diz respeito àquilo que todos nós temos em comum com o mundo considerado natural, ou seja, agir em relação a um meio que exige respostas 
Dossiê: Diálogos interdisciplinares em Psicologia da Educação

| Entre comportamentos, discernimentos e desenvolvimentos: os sujeitos da aprendizagem em quatro movimentos |

| Samuel Edmundo Lopez Bello | Diego Souza Marques |

orgânicas para o nosso bem sobreviver. Os objetos, neste caso, contêm certa dose de demandas básicas enquanto nos encaram, mesmo que ainda não nos separemos conceitualmente deles. Outra, por sua vez, quer que nos formemos como subjetividade a partir de um entorno que é criação dos antecedentes sujeitos já estabelecidos. Estes raciocínios se mesclam, e a passagem de um para o outro também pressupõe um desenvolvimento. Entre este deslocamento do dizer e do ver, o sujeito que emerge também se desenvolve; mas em direção a uma composição que ultrapassa o biológico, o mental e se configura nos limiares do social.

O que está anteriormente desenvolvido como uma espécie de raciocínio que ainda não pode ser entendido como formação subjetiva se refere aqui ao que é prático. $\mathrm{Na}$ crítica a um sujeito que se identifica com o desenvolvimento, o que o antecede não é falta desta faculdade, mas um tipo diferente da mesma que se conecta a outros aspectos da vida. Pensar abstratamente não é, neste caso, um aspecto separado ou consequente de habilidades operatórias ou sensório motoras. Se compõem paralelamente em um processo que conduz à dilatação de uma consciência que incessantemente transforma a reflexão em novas formas motoras. São sínteses que produzem novos polos opostos. E como atração entre eles e sua consequente fusão; as exigências de uma história cultural e social.

A convergência entre estes dois "tipos" de raciocínios pode ser considerada como a formação de um sujeito resultante do processo de aprendizagem. "[...] a unidade dialética desses sistemas no adulto humano constitui a verdadeira essência do comportamento humano complexo" (VYGOTSKY, 2007, p. 11). É o início desta síntese como parte de um processo de formação de subjetividade.

Internalizamos formas culturais de lidar com aquilo que a própria cultura nos lança como demanda, mas sem que já tenhamos feito isso anteriormente. Mistério de um sujeito que se identifica a partir de um desenvolvimento que este meio artificial limita e estimula ao mesmo tempo. E neste processo intrincado, o que se destaca como divergência sutil em relação ao desenvolvimento piagetiano está justamente na questão da aprendizagem.

O desenvolvimento não segue estágios pré-estabelecidos, independentemente de sua sucessão ou coexistência, mas sim depende daquilo que a aprendizagem cria como possibilidades de seu movimento. Desenvolver-se, neste caso, é imprevisível, mas com uma cota limitada de onde pode surpreender. É neste sentido que Vygotsky discorda das experiências de Piaget; pois, para aquele, as situações colocadas estariam além das possibilidades reais de resposta, visto que este buscava um tipo de desenvolvimento específico rumo ao raciocínio lógico e a abstração. No desenvolvimento limitado pelo 
Dossiê: Diálogos interdisciplinares em Psicologia da Educação

| Entre comportamentos, discernimentos e desenvolvimentos: os sujeitos da aprendizagem em quatro movimentos |

| Samuel Edmundo Lopez Bello | Diego Souza Marques |

social, o que pode ser trabalhado tem uma gama maior de possibilidades, embora se restrinja ao que é considerado possível. E a aprendizagem é o espaço deste imprevisível relativamente controlável por determinável contexto.

O que cria a aprendizagem como um processo do qual o desenvolvimento é dependente é um espaço para que o objetivo deste não seja único. Assim, o sujeito que emerge de todo este desdobramento dialético não tem um fim único, mas sim uma diversidade mais alargada de identidades. O que faz parte dele como um ser que aprende, dentro do seu espaço histórico e social, são as aberturas de possíveis, propiciadas pela aprendizagem, conhecidas como zonas de desenvolvimento proximal. O que poderá ser desenvolvido, neste caso, é mais importante em algum momento de formação do que o objetivo final. Assim, o sujeito do desenvolvimento que depende do social, tem a sua identidade marcada por vários níveis de resultado final. Tanto um suposto raciocínio formal quanto uma suposta consciência social têm o mesmo peso na balança, e um não exclui o outro.

Aquilo entendido como nível de desenvolvimento real é a constatação de algo no sentido “já se é capaz de fazer”. Repetir a ação ou aquisição de linguagem; por exemplo. Já o desenvolvimento potencial está além, de uma maneira um tanto quanto peculiar, já que não é definida embora dependa do que é possível de ser desenvolvido em determinado recorte espaço temporal. A zona de desenvolvimento proximal é o território que separa esta distância. “Aquilo que não amadureceu, que não está fechado” (VYGOTSKY, 2007, p. 98), está aberto embora esta abertura também tenha limites possíveis de serem definidos. $\mathrm{E}$ este interstício é o momento da aprendizagem, que vai definir o que vai efetivamente ser desenvolvido ou não, como um jogo de azar onde as combinações podem ser calculáveis.

O que poderá ser desenvolvido não significa romper com alguma concepção de desenvolvimento mecanicista, o que vimos não corresponder com a epistemologia genética de Piaget. O rompimento está mais ligado ao que cria os contornos de uma subjetividade após o processo de aprendizagem. O sujeito, na presente perspectiva, tornou-se identificável por um desenvolvimento resultante de aproximações, ou seja, se houvessem estágios para o seu desenvolvimento seriam definidos por opções que não teriam a reversibilidade do processo como um modo de destacar o alcance ou não de um período, mas sim que cada fase traria novas possibilidades limitadas que criariam um embaralhamento onde é impossível retornar. Se na epistemologia genética é possível desmontar os passos rumo a um objetivo como justamente uma nova etapa superada, aqui, caso imaginássemos um regresso, seria impossível recompor uma zona de desenvolvimento 
Dossiê: Diálogos interdisciplinares em Psicologia da Educação

| Entre comportamentos, discernimentos e desenvolvimentos: os sujeitos da aprendizagem em quatro movimentos |

| Samuel Edmundo Lopez Bello | Diego Souza Marques |

proximal, pois ela poderia desenvolver outras habilidades que não corresponderiam ao resultado anterior. O sujeito se forma irreversível, aparentemente pela sua ampliada gama de possibilidades em se desenvolver futuramente.

O sujeito que se desenvolve além de suas determinações biológicas e aquém do meio social que vive tem suas peculiaridades como formação dependente do aprendizado. Não tem o raciocínio como uma característica destacável, mas, ao mesmo tempo, deve criar uma especificidade nele para iniciar o seu entendimento como tal. Neste processo, o raciocínio considerado superior faz parte de um entendimento do contexto histórico social que é declaradamente arbitrário e limitador das possibilidades.

Para que o sujeito se destaque como resultado de um desenvolvimento, deve ultrapassar estes círculos que se dão por sucessivas ampliações dialéticas. E neste desdobramento onde se limita e se amplia sua capacidade de formação, a aprendizagem tem um papel importante como condutor do qual o desenvolver-se é dependente. Como criação de uma zona proximal onde as possibilidades estão simultaneamente, embora não concretamente, presentes como aberturas para conexões que, mesmo que não infinitas, dão um caráter de imprevisibilidade para este sujeito que se compõe. A subjetividade der'ivada de contextos históricos e sociais dados como limiares tem uma independência regulada por anteriores criações de outras subjetividades, mesmo que impessoalmente. Não adquire contornos, portanto, paradoxais, mais de teses e antíteses ainda provisórias que não determinaram a mais adequada e incerta previsível síntese.

\section{CONCLUSÃO: divergentes aprendizagens e diferentes sujeitos}

Um sujeito da aprendizagem não necessariamente precisa estar restrito à questão do conhecimento. Acomodar, assimilar, absorver, adquirir ou até mesmo construir soam como expressões familiares quando tratamos sobre a questão do aprender no campo educacional. É um conhecimento que atravessa, se internaliza ou mesmo se compõe junto a um suposto sujeito que está em relação a ele. E assim poderia ser entendido um processo de aprendizagem. Vimos que o ato de aprender está atrelado a questões outras que não se estreita necessariamente na questão do conhecer. Subordinado a objetivos mais amplos ou mesmo outros, o processo de aprendizagem é espaço de passagem rumo à formação de determinados tipos de subjetividade.

Nos quatro movimentos que destacamos, há certos diferenciais no que seria esta operação de aprender ao mesmo tempo em que o seu papel nos objetivos gerais muda com 
Dossiê: Diálogos interdisciplinares em Psicologia da Educação

| Entre comportamentos, discernimentos e desenvolvimentos: os sujeitos da aprendizagem em quatro movimentos |

| Samuel Edmundo Lopez Bello | Diego Souza Marques |

sua própria definição. Almejando uma transformação de comportamento ou desenvolvimento mental, cada estrato deu um lugar diverso ao que a aprendizagem faz. De um salto a outro, detectamos que aprender pressupõe certa transformação qualitativa, mesmo que em direções divergentes.

O aprendizado que gera um sujeito comportamental torna-se repertório cada vez mais amplo de possíveis respostas a estes estímulos, e é por isso que tal subjetividade é avaliada pelas suas ações, não levando em conta qualquer interioridade mental. Já na produção do sujeito da percepção destacamos a importância das associações como um primeiro passo que estabelece relações com o todo e, a partir de suas qualidades, uma posterior evocação já determinando o valor do processo de aprendizagem. Aprender é evocar associações passadas, que irão saltar adiante como algo organizado capaz de dar ao sujeito um espaço de identidade. Aprendizagem que tem sentido, pois trouxe à tona novamente (através da evocação) associações potentes para esta constituição de subjetividade. Com esta perspectiva bem definida, o discernimento seria etapa final da formação de uma consciência que pode legislar sobre esse todo e produzir as repartições de onde se confunde e de onde se destaca.

Em outro sentido se desdobra o sujeito que se constituí a partir de uma aprendizagem atrelada ao desenvolvimento. Enfatizamos a relação entre sua prematura forma e a relação dela com objetos que a circundam. Como uma relação que progressivamente vai constituindo uma identidade, o desenvolvimento piagetiano culmina em uma hierarquia do sujeito em relação a este espaço que se difere dele. Os desequilíbrios e reequilíbrios que produzem novas estruturas cognitivas, e configuram os estágios deste desenvolvimento, tem o seu ponto de antecipação e conexão com a aprendizagem. Ela é o elo de ligação entre as passagens, condensando as necessárias assimilações e acomodações para preparar a estrutura para o desequilíbrio seguinte.

Com algumas pequenas diferenças será delineado o sujeito do desenvolvimento atrelado a Vygotsky. Os raciocínios elementares, biológicos e/ou sensório motores, irão ocorrer paralelamente aos superiores, de origem social e dependentes da linguagem. O desenvolvimento deles não se dará por estágios sucessivos, mas por um desenrolar individual e com alguns pontos de inflexão. E nesta parte do processo a aprendizagem se esquematizara, pois, é sua função conectar ambos para o desenvolvimento de novas habilidades, tanto fisiológicas como de empoderamento em relação ao que está demandado como cenário histórico e social. 

quatro movimentos |

| Samuel Edmundo Lopez Bello | Diego Souza Marques |

$\mathrm{Na}$ tentativa de descrever todos estes processos tendo em vista a produção de sujeitos resultantes da aprendizagem como operador dentro de determinada perspectiva, buscamos destacar especificidades em cada movimento. Enquanto há um movimento que tem o aprender como ponto de passagem, dentro de cada uma das abordagens aqui apresentadas, também há um sujeito que constituí por estas práticas, seja ele pré-concebido e/ou em formação imanente a estes processos. Em cada formação de subjetividade que se diversifica, há uma aprendizagem que se apresenta como divergência.

\section{REFERÊNCIAS}

DELEUZE, Gilles. Foucault. Lisboa: Edições 70, 2005. 183 p.

DELEUZE, Gilles. Mil platôs: capitalismo e esquizofrenia. 2. ed. São Paulo: Ed. 34, 2011 2012. v. 5.

FOUCAULT, Michel. A arqueologia do saber. 7. ed. Rio de janeiro: Forense Universitária, 2010. 236 p.

GARDNER, Howard. Estruturas da mente: a teoria das inteligências múltiplas. Porto Alegre: Artes médicas, 1994. 340 p.

KASTRUP, Virginia. A invenção de si e do mundo: uma introdução do tempo e do coletivo no estudo da cognição. Campinas: Papirus, 1999. 216 p.

KÖHLER, Wolfgang. Psicologia da Gestalt. 2. ed. Belo Horizonte: Itatiaia, 1980. 208 p.

PIAGET, Jean. Seis estudos de psicologia. 24. ed. Rio de Janeiro: Forense Universitária, 1999. $136 \mathrm{p}$.

PIAGET, Jean. Epistemologia genética. 3. ed. São Paulo: Martins Fontes, 2007. 123 p.

SILVA, Tomaz Tadeu da. Documentos de identidade: uma introdução às teorias do currículo. 2. ed. Belo Horizonte: Autêntica, 1999. 154 p.

SKINNER, Burrhus Frederic. Sobre o behaviorismo. São Paulo: Cultrix, 1974. 216 p.

VYGOTSKY, L. S. A formação social da mente: o desenvolvimento dos processos psicológicos superiores. 7. ed. São Paulo: Martins Fontes, 2007. 182 p. 